\title{
Female genital mutilation/cutting: changes and trends in knowledge, attitudes, and practices among health care professionals in The Gambia
}

This article was published in the following Dove Press journal:

International Journal of Women's Health

12 April 2016

Number of times this article has been viewed

\author{
Adriana Kaplan Marcusán ${ }^{1-3}$ \\ Laura Riba Singla ${ }^{3}$ \\ Mass Laye ${ }^{3}$ \\ Dodou M Secka ${ }^{3}$ \\ Mireia Utzet ${ }^{4}$ \\ Marie-Alix Le Charles ${ }^{3}$ \\ 'Social Knowledge Transfer/Parc de \\ Recerca UAB - Santander, Universitat \\ Autònoma de Barcelona, Barcelona, \\ Spain; ${ }^{2}$ Interdisciplinary Group for \\ the Study and Prevention of Harmful \\ Traditional Practices, Department \\ of Social and Cultural Anthropology, \\ Universitat Autònoma de Barcelona, \\ Barcelona, Spain; ${ }^{3}$ Wassu Gambia \\ Kafo, Fajara F Section, The Gambia; \\ ${ }^{4}$ Africa and Latin America Research \\ Group, Unit of Biostatistics, Faculty \\ of Medicine, Universitat Autònoma de \\ Barcelona, Barcelona, Spain
}

Background: Female genital mutilation/cutting (FGM/C) is a harmful traditional practice that affects two out of three girls in The Gambia, seriously threatening their life and well-being with severe health consequences. By tracking the reference values established in former research conducted between 2009 and 2011, the objectives of this study are to explore trends and to measure and assess changes in knowledge, attitudes, and practices regarding FGM/C among health care professionals (HCPs) in The Gambia.

Methods: A cross-sectional descriptive study was designed to collect and analyze data from an overall stratified sample consisting of 1,288 HCPs including health professionals and students throughout the six regions of The Gambia. Data were collected by the implementation of a self-administered written knowledge, attitudes, and practices questionnaire between 2012 and 2014.

Results: The results of this study showed that $76.4 \%$ of HCPs are eager to abandon FGM/C, and $71.6 \%$ of them regard it as a harmful practice with negative consequences on life and health. HCPs reported more knowledge and favorable attitudes towards FGM/C abandonment, being better able to identify the practice, more aware of its health complications, and more concerned in their essential role as social agents of change. However, $25.4 \%$ of HCPs still embraced the continuation of the practice, $24.4 \%$ expressed intention of subjecting their own daughters to it, and $10.5 \%$ declared to have performed it within their professional praxis.

Conclusion: Findings confirm progress in knowledge and attitudes regarding FGM/C among HCPs, who are better skilled to understand and manage the consequences. Nevertheless, discrepancies between information, intention, and behavior unveil resistance in practice and proves that FGM/C medicalization is increasing. Thus, there is an urgent need to support HCPs in the integration of FGM/C preventive interventions within the public health system, to address arguments favoring medicalization, and to use data to design appropriate strategies.

Keywords: female genital mutilation/cutting, The Gambia, health care professionals, knowledge, attitudes, practices, changes, trends, sexual and reproductive health

\section{Introduction}

Female genital mutilation/cutting (FGM/C) refers to all procedures involving injury, partial or total removal of the female genital organs for non-therapeutic reasons. ${ }^{1}$ The practice is concentrated in 29 countries of sub-Saharan Africa, the Middle and Far East; and the United Nations Children's Fund (UNICEF) estimates it affects between 125 and 140 million women in the world. ${ }^{2}$ Today's demographic trends associated with the migratory reality and other globalization processes have contributed to the extent of FGM/C worldwide, making it an international phenomenon that transcends geography.
Marcusán

Department of Social and Cultural Anthropology, Wassu-UAB Foundation, Universitat Autònoma de Barcelona,

Bellaterrra 08193, Spain

Tel +34649205108

$\mathrm{Fax}+34935868799$

Email adriana.kaplan@uab.cat
International Journal of Women's Health 2016:8 103-II7

(c) (7) (5) 2016 Kaplan Marcusán et al. This work is published and licensed by Dove Medical Press Limited. The full terms of this license are available at https://www.dovepress.com/terms.php cc) and incorporate the Creative Commons Attribution - Non Commercial (unported, v3.0) License (http://creativecommons.org/licenses/by-nc/3.0/). By accessing the work you hereby accept the Terms. Non-commercial uses of the work are permitted without any further permission from Dove Medical Press Limited, provided the work is properly attributed. For permission for commercial use of this work, please see paragraphs 4.2 and 5 of our Terms (https://www.dovepress.com/terms.php).
Dovepress

http://dx.doi.org/10.2147/IJWH.S102201

\section{3}


$\mathrm{FGM} / \mathrm{C}$ is defined as a set of procedures classified into four major types according to its precise anatomical extent and ascending level of severity: type I (clitoridectomy) refers to partial or total removal of the clitoris or its prepuce; type II (excision) is the partial or total removal of the clitoris and the labia minora, with or without excision of the labia majora; type III (infibulation) involves the narrowing of the vaginal opening through the creation of a covering "seal" formed by cutting and repositioning the inner or outer labia, with or without removal of the clitoris. Type IV includes all other harmful procedures to the female genitalia for non-medical purposes (including pricking, piercing, incising, scraping, and cauterization). ${ }^{1}$

The origins of FGM/C remain uncertain and the prevalence, typology, and circumstances surrounding the practice show wide variations between countries and regions. ${ }^{3}$ Deeply rooted in ancestral tradition, FGM/C has been practiced for centuries and it is surrounded in a complex symbolic cultural meaning. ${ }^{4}$ Although the overall prevalence has declined and the practice has changed to less severe types, continued high exposure to FGM/C seriously threatens the health and well-being of over 30 million girls in the next decade. ${ }^{2}$ Internationally recognized as a breach of human rights, $\mathrm{FGM} / \mathrm{C}$ perpetuates gender inequality and discrimination. As a harmful traditional practice, it is considered an extreme form of violence against women and children that violates the fundamental rights to life, liberty, security, dignity, non-discrimination, and physical and mental integrity. ${ }^{5,6}$

The Gambia is ranked ninth in the world for prevalence of FGM/C with a rate of $76.3 \%$ (78.3\% in 2005/2006), with two out of three girls at risk of being subjected to the practice. ${ }^{6}$ Types I (66.2\%) and II (26.3\%) are the most common, ${ }^{7}$ and the prevalence at subnational level reveals disparities between regions. The areas with highest prevalence are: Basse, in the Upper River Region (99\%); Mansakonko, in the Lower River Region (90.6\%); and Brikama, in the Western Region (84.5\%). By contrast, the areas with lower percentages of women who had any form of FGM/C are Kerewan, in the North Bank Region (49.2\%); and Banjul, the capital city of the country (56.3\%). Slender differences are also found between $\mathrm{FGM} / \mathrm{C}$ rates in urban (74.6\%) and rural $(78.1 \%)$ areas of residence and among those in the lowest wealth quintile (72.7\%) than in the highest (69.8\%). Slight variations by education are also noted in the country, as the prevalence of FGM/C is higher among non-educated women $(76.7 \%)$ than women who completed primary or higher education $(73.9 \%){ }^{6}$
Reasons upholding FGM/C among practicing groups in The Gambia are numerous and diverse, and can be classified into four main categories: hygienic and esthetic, psychosexual, spiritual/religious, and socio-cultural. ${ }^{3}$ Perceived as a women's affair, the $\mathrm{FGM} / \mathrm{C}$ decision-making process is led by female elders, who are key figures in the ceremony arrangements as custodians of the tradition, whereas men are rarely informed about it. ${ }^{8}$ The age at which girls undergo the practice - which can vary from the seventh day of life up to pre-adolescence - seems to be decreasing in The Gambia, with $57 \%$ of girls being subjected to it by the age of five. ${ }^{6}$ Usually performed by specially designated female traditional practitioners, $\mathrm{FGM} / \mathrm{C}$ is also reported to be carried out by health care professionals (HCPs), ${ }^{7}$ prompting an intense debate on medicalization - defined by the World Health Organization (WHO) as a case in which FGM/C is practiced by any category of HCP.

There is ample evidence that FGM/C is closely tied to ethnic affiliation, which seems to be the most decisive factor for its prevalence. ${ }^{4,7}$ With an ethnically diverse population, The Gambia is composed of different groups, which are closely linked through generations of inter-ethnic marriage and by the unifying force of Islam, the major religion in the country. Recent data presented by UNICEF of contrasting prevalence among ethnic groups demonstrate that the highest national prevalence is found amongst Serahuleh (97.8\%), followed by Mandinka (96.7\%), Fula (87.3\%), and Jola $(87 \%)$. In contrast, the practice appears to be less among Serere (43\%) and Wollof (12.4\%). ${ }^{6,9}$

As extensively described in the ethnographic research conducted by the first author of this paper, FGM/C has traditionally been part of the rite of passage to womanhood among certain ethnic groups in the country. ${ }^{10}$ In these cases, FGM/C is the physical phase of a socializing process that molds the attitudes and beliefs of girls and women, consolidating ethnic and gender identity and preparing them for eligibility of marriage. However, over the past generation, several changes have been occurring, and recent research outlines that the physical cutting is progressively being disassociated from the traditional ritual. ${ }^{7,11}$

For decades, the social convention theory at the core of international prevention campaigns has defined FGM/C as a self-enforcing social norm, ${ }^{12}$ identifying it as a customary rule of behavior that occurs under fear of exclusion and that families do it - even when it is known to inflict harm upon girls - because the perceived social benefits are deemed more important than its disadvantages. ${ }^{4}$ While some recent perspectives deny this model and find empirical support in 
individual and family reasons as forces perpetuating the practice, ${ }^{13}$ the original formulation of social convention theory has been further refined and reinterpreted. Along these lines, Shell-Duncan et al regard FGM/C in The Gambia as a peer convention that ensures a woman's status by controlling her body and sexuality through virginity preservation concerns. Therefore, the practice is not linked to marriageability, but seen as a mechanism to facilitate admission into social network and capital, with peer pressure playing a major role in its perpetuation. ${ }^{14}$

Despite the fact that $\mathrm{FGM} / \mathrm{C}$ has no religious origin or justification, ${ }^{15}$ the practice is commonly perceived as an Islamic duty in The Gambia, constituting one of the main arguments invoked for its continuation. ${ }^{8}$

Regarding legal implications, The Gambia had signed national legal conventions that implicitly oppose the practice, but no specific legislation in the country was proposed until December 2015, when The Gambia's National Assembly historically approved $\mathrm{FGM} / \mathrm{C}$ prohibition and criminalization through the amendment of the National Women's Act. Different preventive interventions have been implemented across the country with timid results, but a comprehensive national plan of action towards FGM/C abandonment has yet to be developed.

As a manifestation of gender inequality, FGM/C is deeply entrenched in social, economic, and political structures and must be understood within a context marked by strong gender discrimination that seriously affects the rights of girls and women, ${ }^{5}$ and that influences a low Human Development Index position (155 out of 177). ${ }^{16}$ Despite being granted equal rights as men under the national constitution, women in The Gambia confront a discriminatory family code (customary and Sharia law regulating marriage, widow inheritance, polygamy, divorce, child custody, and women's rights to inheritance), restrictions on resources and assets (discriminatory practices in access to land, financial services, and employment), and restrictions on physical integrity (FGM/C and domestic violence remaining widespread problems together with inaccessible and insufficient maternal health care services). ${ }^{17}$

Although a large body of literature has documented FGM/C risks and impact on health, The Gambia lacked scientific and reliable data on the practice's circumstances and its life-threatening consequences. Acknowledging this gap, two clinical studies were conducted and proved that FGM/C affects girls and women in both the short- and the long-term, ${ }^{18,19}$ with one out of three girls and women presenting with injuries as a consequence of the practice.
These studies also revealed that $\mathrm{FGM} / \mathrm{C}$ increases the risk of complications during childbirth for both the mother and the newborn by 4.5 times, with infant mortality increasing when the mother has undergone the practice. These results highlighted, for the first time, the magnitude of the health consequences associated with FGM/C in The Gambia and emphasized the critical need for specific actions. ${ }^{18,19}$

In addition, a study conducted between 2009 and 2011 examining knowledge, attitudes, and practices (KAP) regarding FGM/C among HCPs in The Gambia, revealed that $42.5 \%$ of health professionals embraced the continuation of $\mathrm{FGM} / \mathrm{C}$, intended to subject their own daughters to it (47.2\%), and have already performed it during their professional duties $(7.6 \%)^{7}$

In the efforts towards management and prevention of $\mathrm{FGM} / \mathrm{C}$, the involvement of HCPs is crucial, as they are respected, influential, and part of the community, holding a strategic position as effective agents of change to ensure that girls at risk and women already suffering FGM/C consequences have access to quality health care services. Therefore, data on KAP can be leveraged to promote its elimination.

The aim of this study is to explore, measure, and assess changes in KAP regarding FGM/C among future and present HCPs in The Gambia. By providing evidence and analysis of what is known, believed, and done by HCPs according to their occupation, sex, and ethnicity, this paper seeks to identify key factors in the process towards the abandonment of FGM/C in the country. The secondary objective is to assess KAP changes over time by tracking the reference values established in the former KAP in-country study carried out between 2009 and 2011.

\section{Methods Design of the study}

A cross-sectional descriptive study was designed to collect and analyze data related to HCPs' perceptions regarding FGM/C, which were classified into the KAP categories. As an attempt to grasp HCPs' tendencies regarding $\mathrm{FGM} / \mathrm{C}$, data were analyzed according to occupation, sex, and ethnic affiliation variables, and quantitative research was combined with extensive literature reviews. The selection of chosen variables responded to their relevance: taking into consideration the characteristics of the research population, the occupation variable is essential to compare current with future HCPs' positions. In addition, a closer look at the most recent data on the issue $e^{4}$ indicates that analysis of sex disaggregated data is fundamental in understanding new tendencies regarding 
the practice, while ethnic affiliation becomes a critical factor, shaping attitudes and practices.

Following the methodology of Kaplan et al, the study was conducted in The Gambia among two specific target groups of health professionals and students, purposely selected from health care facilities and academic centers throughout the six regions nationwide over a 3-year period spanning 2012, 2013, and 2014. ${ }^{7}$

Taking into account the socio-demographic characteristics of the country, the study integrated a multi-ethnic approach and data were collected by a multidisciplinary research team of native and international, female and male professionals, through the implementation of a structured questionnaire. Containing both closed- and open-ended items, the selfadministered KAP questionnaire was handed out in the same format to both target groups, who completed the written interviews individually. All questionnaires were developed in English - the official language of the country - and precise oral instructions were provided by the research team prior to completing the document.

\section{Research population}

The overall stratified sample consisted of 1,288 HCPs, including health professionals and students in The Gambia. The purposive sampling was used within the framework of the National Training Program of HCPs on FGM/C implemented by the non-governmental organization Wassu Gambia Kafo - one of the two research and training stations of the Transnational Observatory of Applied Research and New Strategies for the Management and Prevention of Female Genital Mutilation, held by Wassu-UAB Foundation at the Autonomous University of Barcelona (UAB), which has developed a methodology of research applied to knowledge transfer in cascade to institutions and health care providers for the prevention and care of FGM/C.

The health professional subgroup was composed of nurses (State Registered Nurses, State Enrolled Nurses, and Community Health Nurses), community nurse attendants, midwives, and public health officers, representing the spectrum of formally trained health professionals enrolled in the Public Health System of The Gambia. To reach this category of interviewees, the main public health facilities in the country were covered.

As future health professionals, students of medicine, nursing, midwifery, and public health degrees were also targeted in the study. All students included in this research were aged 18 and over at the date of the interview and in their second year of university onwards, recruited from all the health science schools in The Gambia.

\section{Questionnaire and variables studied}

The KAP questionnaire on FGM/C was composed of 36 statements linked together from the general to the specific, including eleven open- and 25 closed-ended questions on general data and relevant information on FGM/C KAP.

Seven "open" questions were intended to collect sociodemographic information from the respondents (including name of the institution, occupation, age, sex, ethnic affiliation, and date of the interview). There were also 29 assorted statements that were classified into questions regarding knowledge (FGM/C exposure and health consequences, as well as reasons for supporting the practice), attitudes (beliefs and intentions regarding $\mathrm{FGM} / \mathrm{C}$, individual preferences regarding its continuation, possible strategies for its prevention, and perceptions of social expectations), and practices (prevalence of the practice among the target groups and degree to which medicalization occurs).

The pilot study conducted in two regions of the country validated the consistency of the questionnaire design, subsequently consolidated by its implementation through the development of the analogous research in 2009/2011 by the first author of this paper. ${ }^{8}$ Development of scaling-up methods and materials allowed the establishment of a baseline to provide new data of FGM/C reality in The Gambia.

In line with the study protocol and methodology, the KAP questionnaire was designed to guarantee the collection of quality data, taking into consideration the sensitivity of the topic and following a culturally respectful approach.

\section{Ethical aspects}

The study was submitted and approved by The Gambia Government/Medical Research Council Laboratories Joint Ethics Committee (ref: R08002), the scientific ethical committee in The Gambia. All respondents were formally informed about the extent and purpose of the research, and their participation was voluntary and contingent on their personal oral consent, free from any coercion whatsoever. Rigorous privacy and confidentiality of participants' identities was maintained, as the questionnaires were classified through a codification numbering system. The totality of the information and personal data obtained as a result of this research is reasonably guarded against any risk of unauthorized or inappropriate use or disclosure under the custody of Wassu Gambia Kafo. The general aim of the study is to benefit the community by improving information on the research topic through knowledge transfer.

\section{Statistical analyses}

After the data collection phase, a descriptive analysis of the main socio-demographic variables was conducted. 
Prevalence proportions (\%) and 95\% confidence intervals (CIs) regarding, respectively; "knowledge", "attitudes", and "practices" were calculated. In order to detect differences in the responses, each variable was stratified by occupation (health professional or student), sex (male or female), and ethnic group (Mandinka, Wollof, Fula, Serahuleh, Jola, Serere). Prevalence proportions were compared with chisquare tests or Fisher's exact test when appropriate. Statistically significant difference was considered at $P<0.01$ and only relevant outcomes were presented. Data were computerized and double-checked via EpiData and descriptive univariate and bivariate analyses were conducted through $\mathrm{R}$ and STATA.

\section{Limitations}

It cannot be excluded that, as a non-probabilistic technique, the purposive sample can be prone to researcher bias. However, based on the characteristics of the country where it was implemented, the use of the technique was valuable to make generalizations from the sample to the population of interest. There is also the possibility that the research participants increased their knowledge on the study topic prior to completing the KAP questionnaire, although the survey methodology was designed to reduce such biases, hence, fully trained HCPs were not included in the sample population. Moreover, the comparative analysis of the former KAP research may be influenced by the fact that the sample of the study carried out between 2009 and 2011 by the first author of this paper only included HCPs from rural regions, and did not observe the occupation variable. An additional challenge is posed by the fact that variables influencing KAP regarding FGM/C may overlap, with special regard to ethnicity, as ethnic groups may have subgroups that differ with respect to $\mathrm{FGM} / \mathrm{C}$.

\section{Results}

Table 1 shows the profile of the respondents, consisting of 1,288 health professionals and medical students (44\% women and $56 \%$ men), with an average age of 27.9 years $(26 \pm 9.25)$. According to the most recent official published data, ${ }^{9}$ the sample is ethnically representative of the total Gambian population, with a small Mandinka over-representation and a slight under-representation of Serahuleh ethnic group.

\section{Knowledge}

When examining trends regarding FGM/C, there is a variety of factors that condition an individual's position towards the practice. Identifying knowledge of FGM/C is crucial to comprehend the underlying reasons. This study explored HCPs'
Table I Socio-demographic characteristics of the sample population

\begin{tabular}{lll}
\hline & $\mathbf{n}$ & $\%$ \\
\hline Sex & $56 \mathrm{I}$ & \\
Male & 703 & 44.4 \\
Female & & 55.6 \\
Ethnicity & 503 & \\
Mandinka & 126 & 40.3 \\
Wollof & 266 & 10.1 \\
Fula & 23 & 21.3 \\
Serahuleh & 126 & 1.8 \\
Jola & 61 & 10.1 \\
Serere & 143 & 4.9 \\
Other & & 11.5 \\
Occupation & 475 & \\
HP & 813 & 36.9 \\
Student & & 63.1 \\
Area of residence & 690 & \\
Urban & 566 & 55 \\
Rural & $\mathbf{n}$ & 45 \\
Mean age, years & $\mathrm{I}, 256$ & Mean \\
\hline
\end{tabular}

Abbreviation: HP, health professional.

knowledge by framing questions in the socio-cultural context of FGM/C in The Gambia, the practice justifications, and the identification and awareness of its health consequences. Key findings are shown in Table 2.

The majority of HCPs surveyed (96.5\%, 95\% CI: 95.5-97.5) cited tradition as the main reason for FGM/C persistence in the country, while only a quarter of the respondents $(24.6 \%$, 95\% CI: $22.1-27.0)$ believed that the practice is mandatory in Islam. Inter-ethnic analysis shows significant differences, such as that the link between FGM/C and religion is mainly supported by practicing ethnic groups such as Jola (27.8\%, 95\% CI: 18.9-36.8) and Mandinka (24.2\%, 95\% CI: 19.8-28.7), whereas only 5.9\% (95\% CI: 1.3-10.5) of Wollof and 7.8\% (95\% CI 2.9-12.7) of Serere shared the same opinion and, instead, placed more emphasis on the deep roots of the practice in the country.

Results regarding knowledge of FGM/C legal implications show a certain level of confusion among HCPs, since most of them (77.9\%, 95\% CI: 75.6-80.3) identified FGM/C as a human rights violation, but a significant portion $(41.3 \%$, 95\% CI: 38.5-44.1) mistakenly thought that The Gambia held a national legislation banning FGM/C at the time the study was being implemented. Analysis by sex showed that, despite being more aware of the human rights framework $(83.4 \%$, 95\% CI: 80.5 -86.6 vs 76.5\%, 95\% CI: 72.4-80.5), women generally showed more misunderstanding regarding specific legal consequences, as almost half of the female respondents (46.2\%, 95\% CI: 41.9-50.5) reported prohibition of FGM/C in the country (vs $32.4 \%$, 95\% CI: $28.0-36.8$ of men). 


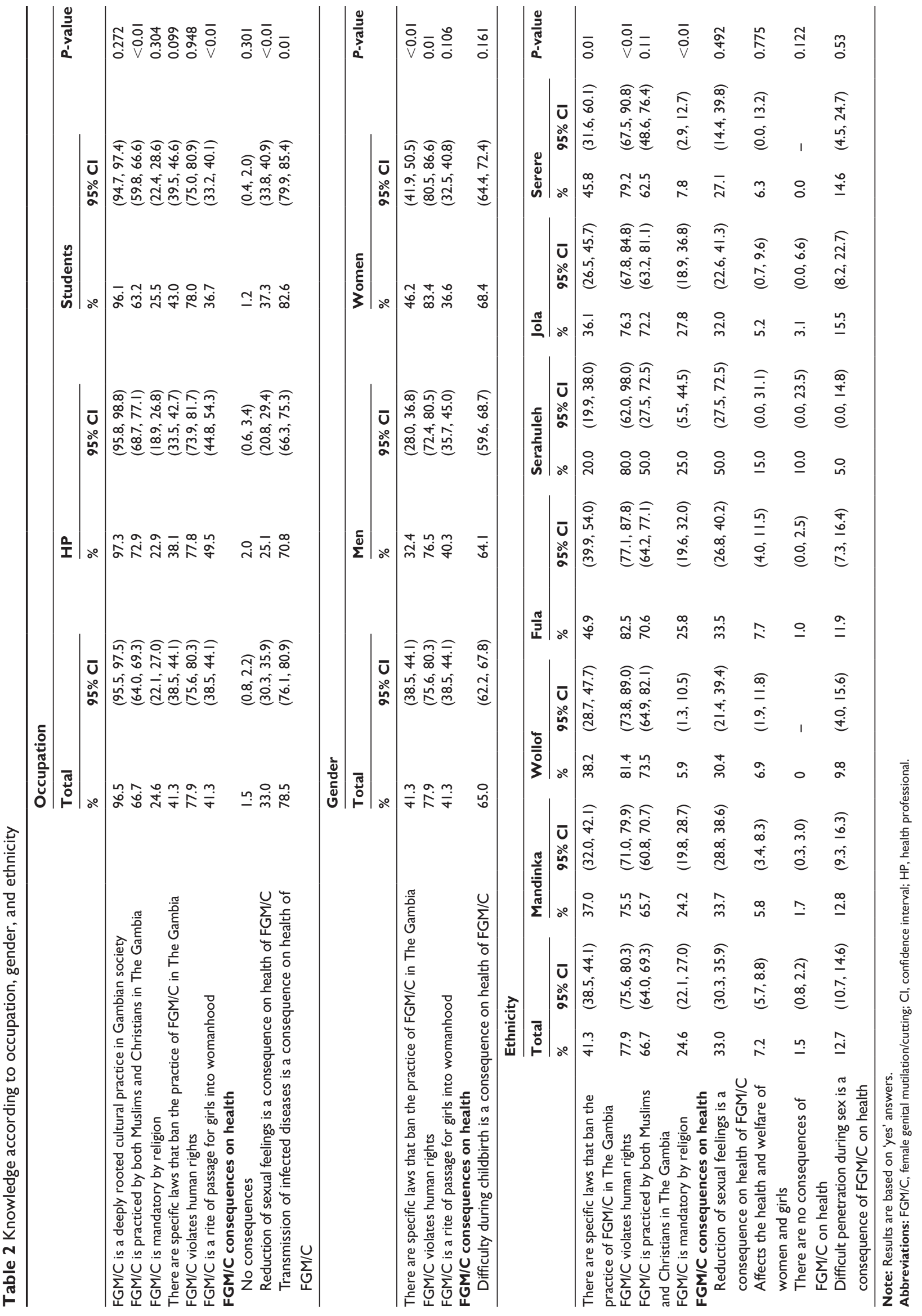


In line with recent research findings, ${ }^{7-11}$ this study confirmed that younger generations tend to disassociate the practice from the traditional ritual. The rate of students surveyed - with a lower average age $(25 \pm 5.2)$ than already working health professionals $(33.1 \pm 8.2)$ - perceiving the practice as part of the rite of passage to womanhood was lower than the percentage of health professionals linking it to the ritual $(36.7 \%, 95 \%$ CI: $33.2-40.1$ vs $49.5 \%$, 95\% CI: 44.8-54.3).

When assessing awareness of FGM/C's impact on health, we observed a general increase in the identification of FGM/ C-related complications, with only $1.5 \%$ (95\% CI: 0.8-2.2) of HCPs stating that the practice has no consequences. HCPs demonstrated remarkable skills in the identification of the different types of consequences, with female HCPs being much better able to recognize a patient with $\mathrm{FGM} / \mathrm{C}$ complications than their male colleagues $(63.9 \%, 95 \% \mathrm{CI}$ : 63.6-75.2 vs $53.1 \%$, 95\% CI: 45.8-60.2). The transmission of infectious diseases was the most frequently reported consequence (78.5\%), closely followed by bleeding $(72.8 \%$, 95\% CI: 76.1-80.9). Obstetric and sexual complications were also recognized by the respondents, since difficulty during delivery was commonly identified as a health risk $(65 \%, 95 \%$ CI: 62.2-67.8), and decreased sexual feelings were also mentioned (33\%, 95\% CI: 30.3-35.9). By analyzing the data with the occupation variable, it can be observed that students have slightly more knowledge than health professionals. Students also showed better identification of the sexual consequences of the practice $(37.3 \%, 95 \%$ CI: $33.8-40.9$ vs $25.1 \%, 95 \%$ CI: 20.8-29.4) and higher recognition of the risk of transmission of sexually transmitted diseases (82.6\%, 95\% CI: 79.9-85.4 vs $70.8 \%, 95 \%$ CI: $66.3-75.3)$.

\section{Attitudes}

A review of trends in HCPs' attitudes towards FGM/C was carried out by exploring their opinions on the feasibility of the abandonment of the practice in The Gambia, and on the possible strategies and social actors involved in the debate (including religious leaders, men, and HCPs themselves). In addition to their impression of those who practice FGM/C, respondents were also asked whether they support the continuation of FGM/C and whether they intend to subject their own daughters to it. Key findings are shown in Table 3.

Regarding attitude towards FGM/C, almost three out of four HCPs (71.6\%, 95\% CI: 69.1-74.1) considered FGM/C a harmful practice, while $28.4 \%$ of them defined it as good or neither good nor bad. Despite not finding significant differences in knowledge, sex differences in support of the practice showed that a higher percentage of women have a negative perception of $\mathrm{FGM} / \mathrm{C}$, and consider it a harmful practice (77.4\%, 95\% CI: $74.2-80.5$ vs $64.7 \%$, 95\% CI: $60.7-68.8$ ). An overall negative opinion of the practice can be linked to the fact that the majority of HCPs surveyed $(75.4 \%, 95 \%$ CI: 73.0-77.8) would approve legislation banning FGM/C in The Gambia, although this was more commonly shared among HCPs from non-practicing ethnic groups (Wolof and Serere). The vast majority of female HCPs $(81.1 \%, 95 \%$ CI: 78.2-84.1) were in favor of a national legislation criminalizing the practice, whereas a lesser degree of support was shown by men $(68.2 \%, 95 \%$ CI: 64.2-72.1).

When questioned about its continuation, a quarter of the respondents (25.4\%, 95\% CI: $22.9-27.8)$ stated that the practice should continue. Among those who adhere to FGM/C abandonment, the practice's negative impact on women's health and welfare was given as the main reason to stop (67.2\%, 95\% CI: 64.4-70.0), while violation of human rights was also invoked by $16.7 \%$ (95\% CI: $14.5-18.8)$ of them as a motivating factor. An analysis of data by sex revealed that women show stronger opposition to the practice and less support to its continuation than their male colleagues $(21.3 \%$, 95\% CI: $18.1-24.4$ vs $29.5 \%$, 95\% CI: $25.6-33.4$ ), bringing these figures along the same lines as the previous study results. ${ }^{7}$ Despite a general tendency toward abandonment, an inter-ethnic analysis unveiled several disparities. Although the most support for FGM/C continuation came from HCPs belonging to ethnic groups with higher FGM/C prevalence Mandinka (33.1\%, 95\% CI: 29.0-37.5), Fula (27\%, 95\% CI: 21.9-32.8), and Jola (24.6\%, 95\% CI: $17.8-32.9)$, it was also among these groups that the major decrease of support to the practice, compared to $2009 / 2011$ results, was found (57.3\%, $42.9 \%$, and $39 \%$ respectively).

Despite the fact that most of the HCPs demonstrated a certain degree of knowledge on FGM/C's negative impact on health, and that only $14.5 \%$ (95\% CI: $12.5-16.5)$ of the total considered it a good practice, $24.4 \%$ (95\% CI: $22.0-26.8)$ of the respondents ( $47.2 \%$ in 2009/2011 study) declared their intention of having FGM/C performed on their daughters. While these findings may appear paradoxical, they can be understood by considering the social benefits perceived by the respondents. Following the same pattern, findings among Jola HCPs revealed that, although only $18.3 \%$ considered FGM/C a good or neither good nor bad practice, $30.5 \%$ of them expressed their support to practicing families. Also regarding intention of performing $\mathrm{FGM} / \mathrm{C}$, remarkable differences by ethnic affiliation were found, with higher percentages among Mandinka (31.3\%, 95\% CI: 26.5-36.1), 


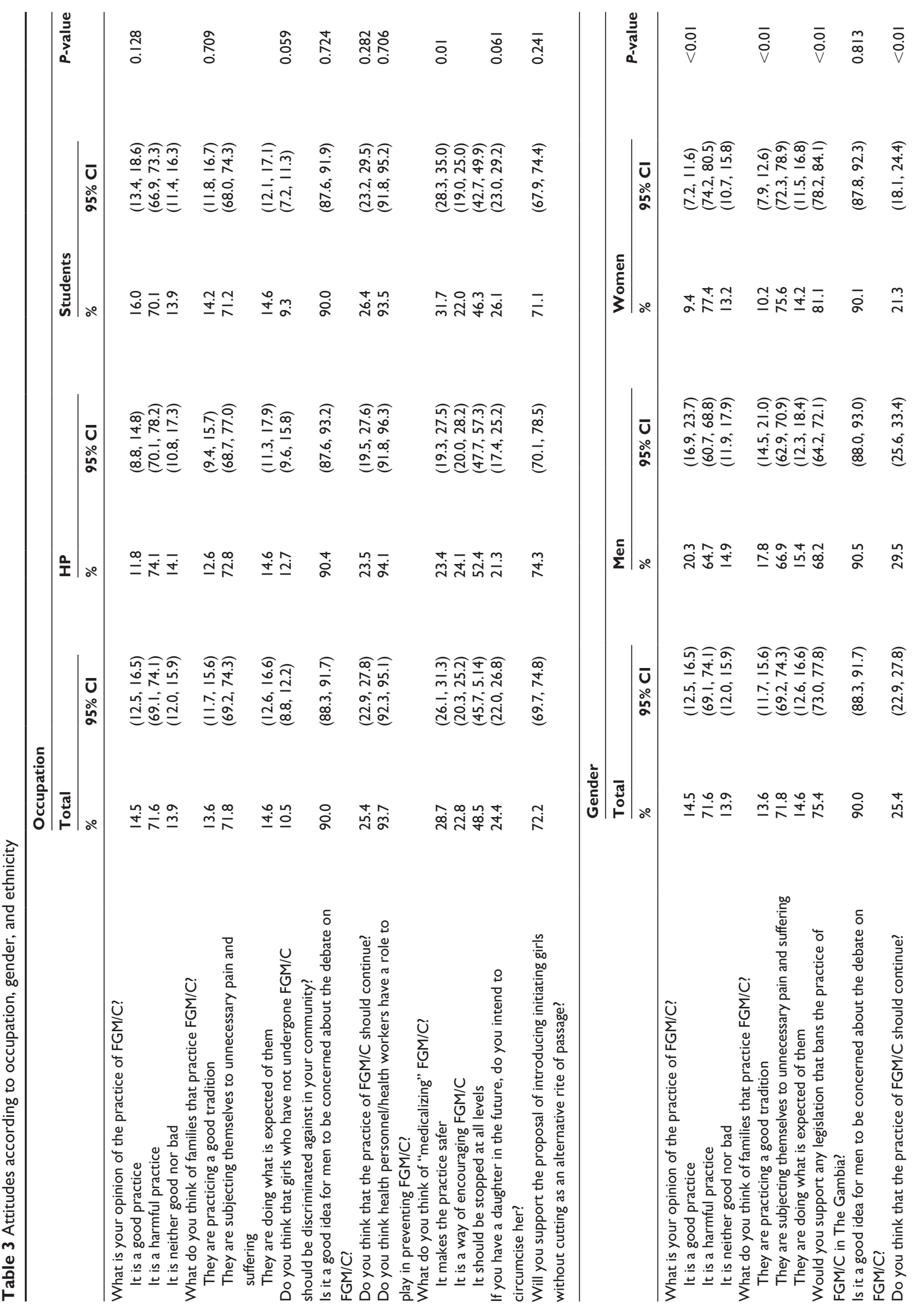




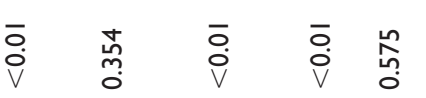

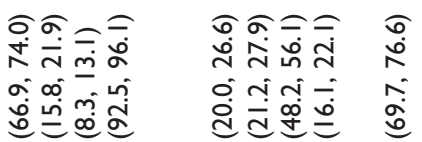

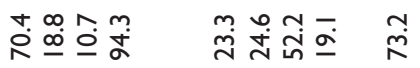

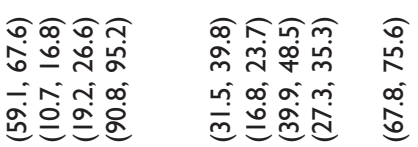

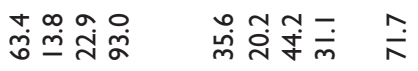

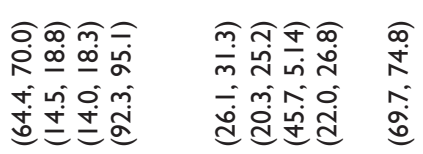

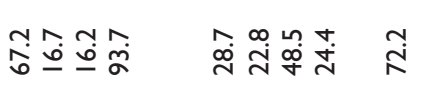

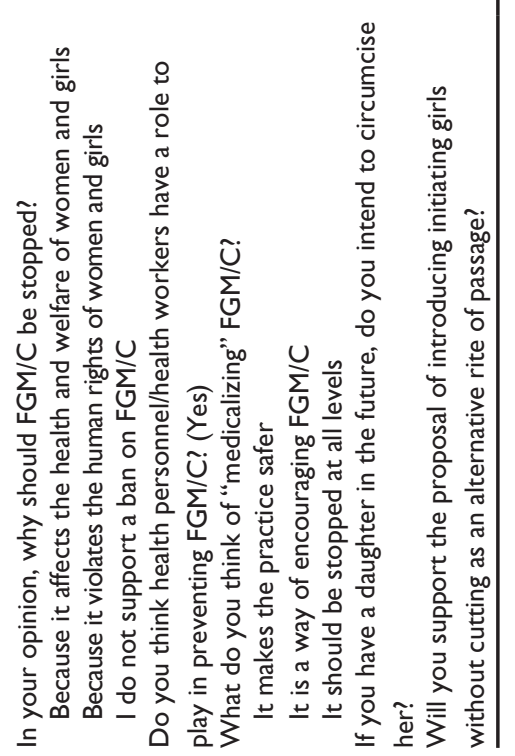

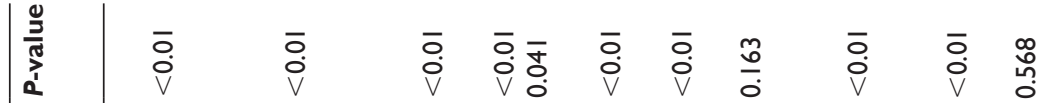

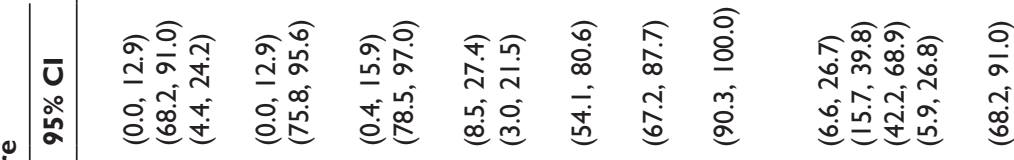

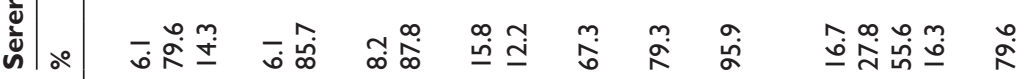

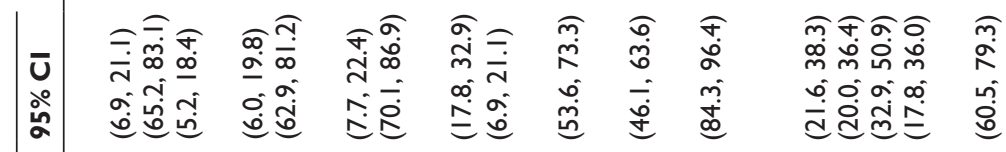

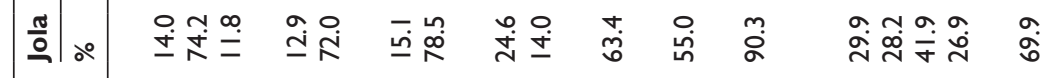

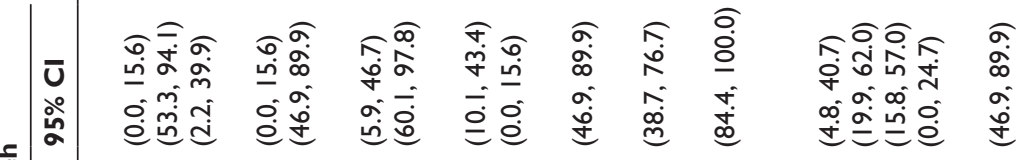

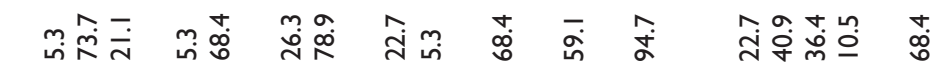

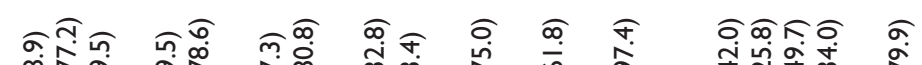

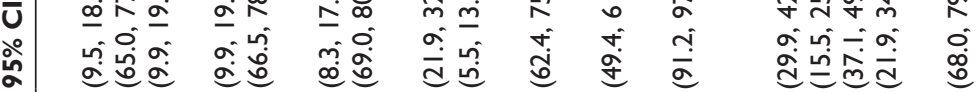

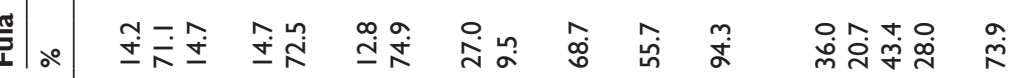

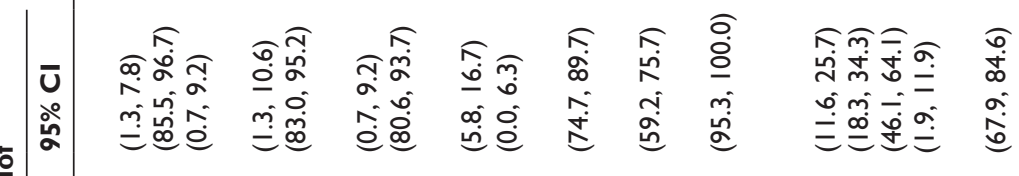
움ㅇํ

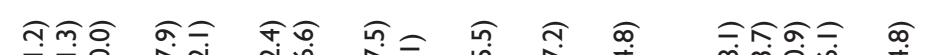

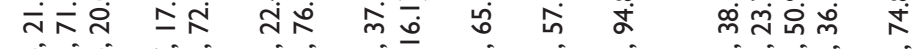

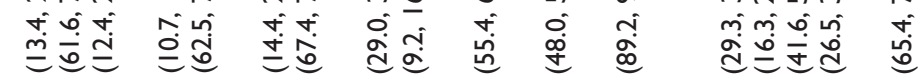

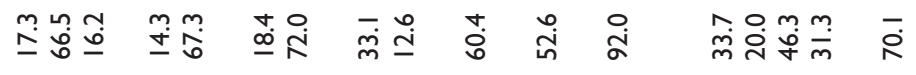

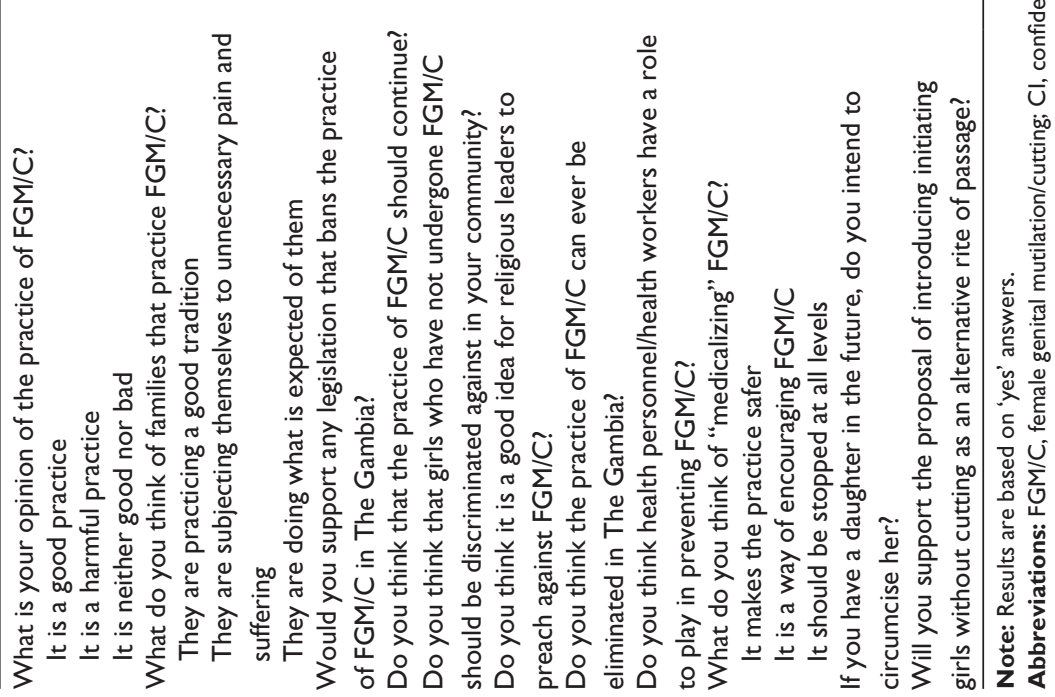


Fula (28\%, 95\% CI: 21.9-34.0), and Jola (26.9\%, 95\% CI: 17.8-36.0). However, support was not as high as prevalence in any ethnic group, and a huge decline in this rate was highlighted in contrast to 2009/2011 figures (Mandinka, 64.3\%; Jola, 47.5\%; and Fula, 43.6\%). When cross-referencing the data according to sex, some divergences were found, with special emphasis on Mandinka women, whose intention to perform FGM/C on their daughters was half when compared to men from the same ethic group (34.9\% vs 65.1\%). A very small presence of discriminatory attitudes toward women and girls not undergoing $\mathrm{FGM} / \mathrm{C}$ were reported by both men and women.

Regarding strategies to prevent the practice, the introduction of an alternative ritual avoiding any mutilation was supported by a significant $72.2 \%$ (95\% CI: 69.7-74.8) of the HCPs surveyed. Moreover, almost all of the respondents (90\%, 95\% CI: 88.3-91.7) agreed on the need for men to take part in the debate, while religious leaders' involvement showed less support (67.2\%, 95\% CI: 64.4-70.0). Nonpracticing ethnic groups showed more optimistic predictions about the feasibility of abandoning FGM/C in the country (Serere, 79.3\%, 95\% CI: 67.2-87.7; Wolof, 68.1\%, 95\% CI: $59.2-75.7)$ than traditionally practicing communities, who were more reluctant to this possibility (Mandinka, 52.6\%, 95\% CI: 48.0-57.2; Jola, 55\%, 95\% CI: 46.1-63.6).

Regarding social actors participating in the process of social change, 93.7\% (95\% CI: 92.3-95.1) stated that HCPs have a key role to play in preventing FGM/C. However, a significant percentage of HCPs (28.7\%, 95\% CI: 26.1-31.3) saw medicalization as a means of controlling and making the practice safer, with men showing more support than women (35.6\%, 95\% CI: $31.5-39.8$ vs 23.3\%, 95\% CI: 20.0-26.6); and more students than health professionals considered FGM/C medicalization safer (31.7\%, 95\% CI: 28.3-35.0 vs $23.4 \%$, 95\% CI: 19.3-27.5). Despite a general decrease in its support, medicalization was found to remain more accepted among Fula (36\%, 95\% CI: 29.9-42.0), Mandinka (33.7\%, 95\% CI: 29.3-38.1), and Jola (29.9\%, 95\% CI: 21.6-38.3).

\section{Practices}

This study explored HCPs' practices regarding FGM/C through the design of specific questions addressing the prevalence of the practice among their families, as well as focusing on whether and to which extent FGM/C is medicalized.

As shown in Table 4, a total of $71.5 \%$ (95\% CI: 68.9-74.0) of HCPs reported that FGM/C is practiced in their family or household, this rate being in line with the national prevalence in The Gambia (76.3\%). When this was examined according to occupation, results indicated lower prevalence among students' families than among health professionals' families $(69.3 \%$, 95\% CI: $66.0-72.5$ vs $75.4 \%$, 95\% CI: 71.4-79.4). An intra-ethnic analysis of these data revealed that $\mathrm{FGM} / \mathrm{C}$ was most commonly performed among Serahuleh communities (90.9\%, 95\% CI: 78.6-100.0), followed by Mandinka (89.6\%, 95\% CI: 86.9-92.4), Fula (85\%, 95\% CI: 80.6-89.4), and Jola (79.5\%, 95\% CI: 72.3-86.7), whereas traditionally non-practicing ethnic groups had lower FGM/C prevalence rates (Serere 43.3\%, 95\% CI: 30.7-56.0; Wollof 23.4\%, 95\% CI: 15.9-30.9). These figures follow the same pattern as the latest available data on FGM/C prevalence according to ethnicity, ${ }^{7}$ strengthening the robustness of the study outcomes.

Regarding the question of having ever performed FGM/C, $10.5 \%$ (95\% CI: 7.9-13.7) of HCPs declared to have performed it during their medical praxis (only working health professionals' responses were considered in questions referring to medical praxis, as considered not applicable for health care students). A subject of ongoing debate in the country, this study found that, despite men embracing medicalization in higher percentages than women, the act of medicalizing FGM/C is much more frequently carried out by female (12\%, 95\% CI: 8.5-16.7) than male HCPs $(6.2 \%, 95 \% \mathrm{CI}$ : 3.5-10.8). Besides, an inter-ethnic insight raised extreme discrepancies among those who declared to have performed it, as $10.6 \%$ (95\% CI: 6.7-16.3) of Mandinka, 10.6\% (95\% CI: 4.6-22.6) of Jola, 9.5\% (95\% CI: 3.8-22.1) of Wollof, and $7 \%$ (95\% CI: 3.2-14.4) of Fula HCPs admitted to have carried out the practice as health professionals, while $0 \%$ of Serere did. Despite holding almost universal FGM/C prevalence, Serahuleh HCPs surveyed in this study showed very low rates of medicalization, which could be related to the circumstances surrounding the procedure in their community, commonly carried out in babies by traditional female practitioners.

\section{Discussion}

To explore dissonances among HCPs' KAP regarding FGM/C, data disaggregation by occupation, sex, and ethnicity allows an accurate analysis of the reasons for the results obtained.

Regarding knowledge, these findings demonstrated that HCPs are better informed regarding FGM/C. In contrast to 2009/2011 results, the great majority of participants invoked tradition as the main reason for the practice's perpetuation, showing a clear break with religious motivations based on the misconception of FGM/C being a religious duty $(53.8 \%)$. 


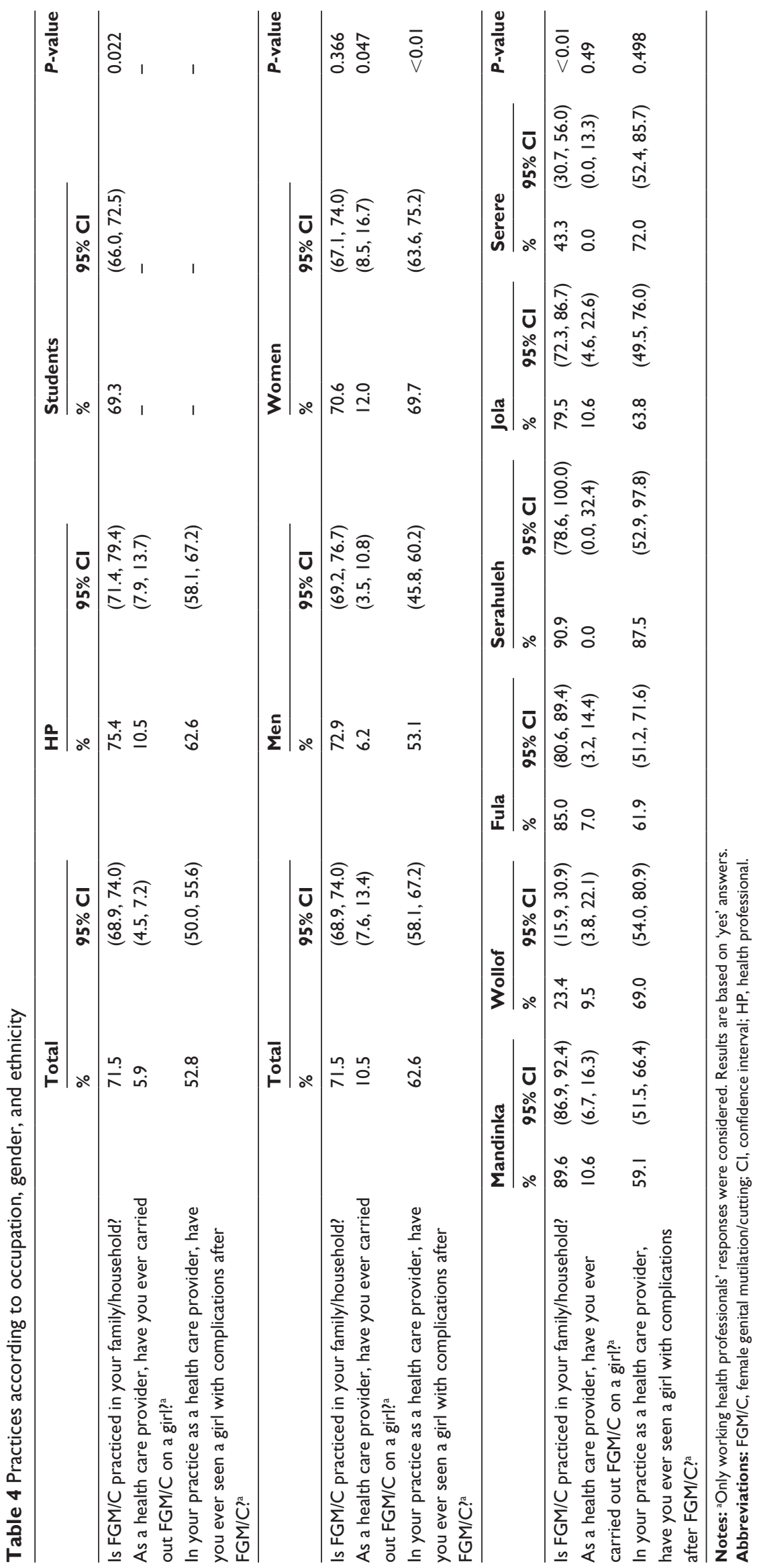


This fact is still more striking when considering that any ethnic group assumed religion as the main justification to legitimize the practice, while in 2009/2011, Fula and Mandinka HCPs cited this link as the primary reason to encourage FGM/C continuation. This swap can be considered a result of the effort to disassociate FGM/C from Islam through the implication and sensitization of religious leaders in FGM/C prevention initiatives that have taken place in The Gambia during the last several years.

In addition, HCPs extensively recognize $\mathrm{FGM} / \mathrm{C}$ as a human rights abuse, with almost $80 \%$, especially women, being aware of $\mathrm{FGM} / \mathrm{C}$ violating fundamental rights. In contrast, the false perception of a current law prohibiting FGM/C in the country is shared among almost half of the respondents, with special support from female HCPs. While more knowledge regarding the human rights framework is related to human rights-based approaches fostered in The Gambia, general misunderstanding of national legislation can be associated with muddled speeches delivered during some of the anti-FGM/C campaigns that could have contributed to driving the practice to private settings under fear of prosecution.

The recognition of FGM/C implications by HCPs is considered an essential condition for them to provide adequate health care assistance to women already living with the complications, as well as to promote prevention. In this sense, findings demonstrated that $98.5 \%$ of HCPs are aware of the practice having consequences, whose recognition has increased when compared to the 2009/2011 study (97.9\%). These results suggest that capacity-building strategies have had a positive impact on the acknowledgment of HCPs in The Gambia, where systematic training campaigns specially focused on the health sector may have enhanced specific knowledge on FGM/C and health. ${ }^{20}$ In addition, while intra-sex and inter-ethnic analysis showed no significant differences with reference to knowledge, an inter-occupation insight indicates that students are better equipped to recognize sexual consequences, possibly due to FGM/C inclusion in the academic curricula of all health schools nationwide, and because of sexual education and HIV/AIDS awareness raising campaigns, which would explain why sexually transmitted diseases remain the most commonly identified FGM/C risk.

According to the study results, HCPs exhibit positive attitudes towards FGM/C prevention, with almost three out of four willing to stop the practice, and considered a harmful procedure by the great majority of them. Linked to the increase in knowledge on the negative effects, ${ }^{21}$ the opposition to FGM/C is particularly noticeable among female HCPs, whose low degree of support for the practice $(21.3 \%)$ contrasts the $64.2 \%$ of women who, according to the latest available data by UNICEF, think FGM/C should continue in The Gambia, thus suggesting that "health professional identity" could have a strong influence on shaping attitudes toward FGM/C.

Other indicators of favorable shifts in HCPs' position are the wide support of legal mechanisms to prevent the practice and an initiation without cutting alternative, as well as the effective incorporation of social actors in the debate on FGM/C. While the 2009/2011 study reflected strong resistances of female HCPs to the inclusion of men, present results show that HCPs almost universally defend men taking part in it. This is consistent with a KAP study on Gambian men, ${ }^{10}$ concluding that those aware of FGM/C's negative impact - with special focus on sexual complications affecting both partners - wish to get involved in its prevention. These findings describe an "opening-up" of the FGM/C debate and lower rates of discriminatory attitudes towards those who decide not to undertake the practice. This indicates that the sense of social obligation and peer pressure regarding FGM/C is low and decreasing among HCPs. Moreover, respondents position themselves in the front line of FGM/C prevention efforts, as the vast majority declared they have a key role to play, thus revealing a substantial increase from 2009/2011 findings (73\%) and a growing recognition of $\mathrm{FGM} / \mathrm{C}$ as a public health issue in the country.

However, paradoxical findings highlight that over $25 \%$ of HCPs still embrace the continuation of the practice, with similar rates of intention of subjecting their own daughters to it. A concerning rate of support for $\mathrm{FGM} / \mathrm{C}$ remains among HCPs, although data tracking over time demonstrates a reduction of its support by half when compared to 2009/2011 results, with $42.5 \%$ of $\mathrm{HCPs}$ declaring they wanted the practice to continue.

In line with this declining pattern, the study shows that medicalization is less favored than in 2009/2011, although it is still supported by almost $30 \%$ of the respondents, who regard medicalization as a means of controlling the practice and making it safer. This perception, opposing any professional ethics code and publicly condemned by WHO, was mostly shared by traditional practicing groups that regard FGM/C as a religious obligation, while non-practicing groups showed their support to stop medicalization at all levels. Therefore, an inter-ethnic analysis reveals that those who link FGM/C to religion might show higher resistance to its abandonment, and tend to perceive medicalization as a way 
of maintaining the practice while reducing the incidence of its consequences.

Indeed, the record of improved knowledge and attitudes in contrast to relatively large support for FGM/C continuation and significantly increased medicalization rates puts the focus of this study on HCPs' practices. As observed, FGM/C is not homogeneously performed, and ethnicity remains a determinant factor in its prevalence, prevailing over professional identity. Therefore, HCPs from traditionally practicing groups are more likely to support its continuation and to subject their daughters to it. Likewise, the study's overall prevalence rate is slightly lower than the national rate and shows a decreasing tendency among younger generations.

Compared to the baseline established by the 2009/2011 KAP study, findings demonstrate that HCPs are more equipped with knowledge regarding $\mathrm{FGM} / \mathrm{C}$, not only being able to list its risks in the theoretical arenas, but also recognizing a patient suffering $\mathrm{FGM} / \mathrm{C}$ consequences during their professional praxis. This indicates a significant improvement in the quality of the health care services they provide, which might be as a result of training initiatives focused on strengthening their capacity to prevent FGM/C. Despite this progression, analysis by sex unveils enormous disparities, demonstrating that female HCPs are almost three times more able to identify FGM/C effects in a patient than male professionals (in comparison to 2009/2011 results which reported $7.6 \%$ of medicalization among HCPs in rural areas), thus confirming that medicalization not only remains a reality in The Gambia, but has become an increasing phenomenon in its public health services. Moreover, these results highlight the need for mechanisms for HCPs to be able to successfully transfer theoretical knowledge into practice.

With regard to medicalization, increasing attitudes of opposition are in contrast with increasing rates of HCPs' performing it within their professional practice. These results reveal discrepancies between attitudes and practices, especially significant under an analysis by sex as, despite manifesting less support, the percentage of female HCPs declaring to have performed medicalization is almost twice the males' average. These findings suggest that female HCPs could be facing higher demand to medicalize the practice, and that, even when brought to the medical setting, FGM/C is regarded as a women's issue to be performed by women to women.

\section{Conclusion}

When exploring KAP regarding FGM/C among HCPs, significant differences by occupation, sex, and ethnicity draw the patterns of the practice's new tendencies. Evidence provided by this study confirms that a gradual disassociation between $\mathrm{FGM} / \mathrm{C}$ and the traditional ritual is occurring in The Gambia. Similarly, the overall support of the practice seems to be declining in a national context of wider debate on the subject, where preventive interventions may have had a positive impact in deconstructing beliefs linking FGM/C to male circumcision and religion. In this slow transformation, men are more eager to take part and HCPs are aware of their decisive role in preventing $\mathrm{FGM} / \mathrm{C}$, which is regarded as a public health issue.

In the analysis of the interconnection between KAP regarding FGM/C, a link between increased knowledge and less supportive attitudes was found. Indeed, the study reports more information on $\mathrm{FGM} / \mathrm{C}$ 's negative consequences as the main reason to support its abandonment among HCPs, who, despite a need for improvement of the practical recognition of consequences in patients, demonstrate better skills to understand, manage, and prevent $\mathrm{FGM} / \mathrm{C}$ as part of their professional duty. Nevertheless, remaining resistances embracing the continuation of the practice suggest that internalization of the health risks is not the only factor involved in the effective change towards prevention.

Since 2009/2011, HCPs' attitudes have moved to more favorable positions regarding $\mathrm{FGM} / \mathrm{C}$ abandonment, with women leading this trajectory and taking a firmer stand against its continuation. Although male HCPs are stronger supporters of the practice, they manifest increasing willingness to take part in its prevention, indicating that the gap in female and male positions toward FGM/C is narrowing. Despite sex and professional identity variables being relevant to the interpretation of some of the results, ethnicity is confirmed as the prevailing factor molding attitudes and practices. In this sense, ethnic identity may influence and overlap with other variables of $\mathrm{FGM} / \mathrm{C}$, and the multidimensionality of the issue stresses the need to design and implement holistic interventions, formulated according to local realities that take into consideration differences among population groups.

From a preventive perspective, while knowledge and attitudes regarding $\mathrm{FGM} / \mathrm{C}$ follow a general trend towards improvement, HCPs' practices do not mirror the same pattern, and our findings do not describe a one-way linear sequence between KAP in the study area. However, higher rates of awareness and favorable attitudes suggest that Gambian HCPs might potentially be prepared for behavior change towards abandonment. In these circumstances, the motivational balance of HCPs should be further assessed to understand which factors prevent them from acting in 
accordance with their individual inclinations, as well as to provide tools and support for the universal integration of FGM/C preventive strategies within their professional activity in the public health system.

This study also shows that FGM/C medicalization is increasingly performed by HCPs in The Gambia. In this regard, figures on female HCPs opposing it but, at the same time, performing FGM/C as health personnel, suggest they are dealing with a certain degree of pressure from families demanding the practice to be performed on patients. In view of this situation, there is a critical and urgent need to provide exhaustive information on medicalization rates in the country-almost not reported in the latest available data of international bodies-as well as to explore the reasons and motivations for HCPs to perform it. Similarly, it is extremely important to clarify confusing messages and address arguments that reinforce the idea of medicalization being a solution to FGM/C. In this sense, evidence on KAP of HCPs must be made explicit and public to influence peers' perceptions, and must be used to design appropriate prevention strategies based on HCPs' legitimacy towards an actual and stable abandonment of FGM/C in The Gambia.

\section{Acknowledgments}

The completion of this study has been made possible thanks to the work of Wassu Gambia Kafo personnel, with special regards to the training and research team members, who offered their expertise and professionalism. We would also like to thank the HCPs who agreed to participate in the research and the close collaboration of the Gambian health and academic institutions, whose collaboration was fundamental for its development. Likewise, we acknowledge Diputación Foral de Álava/Arabako Foru Aldundia, "La Caixa" Foundation and the Catalan Agency for Development Cooperation (ACCD) for having the confidence and providing the financial support that has made this study possible. We are especially grateful to Mr Seny Mendy, whose dedication and determination opened new doors for the prevention of FGM/C in The Gambia.

\section{Disclosure}

The authors have no conflicts of interest to disclose in this work.

\section{References}

1. OHCHR, UNAIDS, UNDP, UNECA, UNESCO, UNFPA, UNHCHR, UNICEF, UNIFEM, WHO. Eliminating female genital mutilation: an interagency statement. Geneva: World Health Organization; 2008. Available from: http://www.unfpa.org/publications/eliminating-femalegenital-mutilation-interagency-statement. Accessed February 8, 2016.
2. Unicef. Female genital mutilation/cutting: a statistical overview and exploration of the dynamics of change. Unicef; 2013. Available from: http://www.unicef.org/publications/index_69875.html. Accessed February 8, 2016.

3. Unicef. The dynamics of social change: towards the abandonment of female genital mutilation/cutting in five African countries. Florence, Italy: UNICEF, Innocenti Research Centre; 2010. Available from: http:// www.unicef-irc.org/publications/618. Accessed February 8, 2016.

4. Kaplan A, Hechavarría S, Puppo N. Manual on Female Genital Mutilation/Cutting for health professionals. Bellaterra: Wassu-UAB Foundation; 2015.

5. United National Population Fund. Implementation of the international and regional human rights framework for the elimination of female genital mutilation. UNFPA; 2014. Available from: http://www. unfpa.org/publications/implementation-international-and-regionalhuman-rights-framework-elimination-female. Accessed February 8, 2016.

6. Unicef. GAMBIA. Statistical profile on Female Genital Mutilation/ Cutting. New York: Unicef; 2014. Available from: http://data.unicef.org/ corecode/uploads/document6/uploaded_country_profiles/corecode/222/ Countries/FGMC_GMB.pdf. Accessed February 8, 2016.

7. Kaplan A, Hechavarría S, Bernal M, Bonhoure I. Knowledge, attitudes and practices of female genital mutilation/cutting among health care professionals in The Gambia: a multiethnic study. BMC Public Health. 2013; $13: 851$

8. Kaplan A, Cham B, Njie LA, Seixas A, Blanco S, Utzet M. Female genital mutilation/cutting: the secret world of women as seen by men. Obstet Gynecol Int. 2013;2013643780.

9. Unicef. The Gambia Multiple Indicator Cluster Survey 2010. Banjul: Unicef; 2011. Available from: http://www.childinfo.org/files/MICS4_ Gambia_2010_FinalReport_Eng.pdf. Accessed February 8, 2016.

10. Kaplan A. De Senegambia a Cataluña: procesos de aculturación e integración social [From Senegambia to Calatonia: acculturation and social integration processes]. Barcelona: Fundación "La Caixa"; 1998. Spanish.

11. United Nations. Changing a harmful social convention, female genital mutilation/cutting. Florence, Italy: UNICEF Innocenti Research Center; 2005.

12. UNDP/UNFPA/WHO/World Bank Special Programme of Research, Development and Research Training in Human Reproduction. Dynamics of decision-making and change in the practice of female genital mutilation in the Gambia and Senegal: social science policy brief. WHO; 2010. Available from: http://www.who.int/reproductivehealth/ publications/fgm/rhr_hrp_10_16/en/. Accessed February 8, 2016.

13. Efferson C, Vogt S, Elhadi A, Ahmed Hel F, Fehr E. BEHAVIOR. Female genital cutting is not a social coordination norm. Science. 2015;349(6255):1446-1447.

14. Shell-Duncan B, Wander K, Hernlund Y, Moreau A. Dynamics of change in the practice of female genital cutting in Senegambia: Testing predictions of social convention theory. Soc Sci Med. 2011; 73(8):1275-1283.

15. Unicef. Female Circumcision ( $F G M / C)$ : Between the incorrect use of science and the misunderstood doctrine. Executive Summary. Egypt, Cairo: UNICEF; 2013. Available from: http://www.unicef.org/mena/ MENA-Final_English_FGM_summary.pdf. Accessed February 8, 2016.

16. United Nations Development Programme. Human development report 2014: sustaining human progress: reducing vulnerability and building resilience. UNDP; 2014. Available from: http://www.undp.org/content/ dam/undp/library/corporate/HDR/2014HDR/HDR-2014-English.pdf. Accessed February 8, 2016.

17. OECD Development Centre. Social Institutions \& Gender Index. 2014 Synthesis Report. OECD Development Centre; 2015. Available from: http://www.oecd.org/dev/development-gender/BrochureSIGI2015web.pdf. Accessed February 8, 2016.

18. Kaplan A, Hechavarría S, Martín M, Bonhoure I. Health consequences of female genital mutilation/cutting in the Gambia, evidence into action. Reprod Health. 2011;8:26. 
19. Kaplan A, Forbes M, Bonhoure I, et al. Female genital mutilation/cutting in The Gambia: long-term health consequences and complications during delivery and for the newborn. Int $J$ Womens Health. 2013;5:323-331.

20. Johansen RE, Diop NJ, Laverack G, Leye E. What works and what does not: a discussion of popular approaches for the abandonment of female genital mutilation. Obstet Gynecol Int. 2013;2013:348248.
21. Shell-Duncan B, Herniund Y. Are there "stages of change" in the practice of female genital cutting?: Qualitative research findings from Senegal and The Gambia. Afr J Reprod Health. 2006;10(2):57-71.
International Journal of Women's Health

\section{Publish your work in this journal}

The International Journal of Women's Health is an international, peerreviewed open-access journal publishing original research, reports, editorials, reviews and commentaries on all aspects of women's healthcare including gynecology, obstetrics, and breast cancer. The manuscript management system is completely online and includes

\section{Dovepress}

a very quick and fair peer-review system, which is all easy to use. Visit http://www.dovepress.com/testimonials.php to read real quotes from published authors.

Submit your manuscript here: http://www.dovepress.com/international-journal-of-womens-health-journal 